\title{
Risk Assessment of Surface Water Contamination by Herbicide Residues: Monitoring of Propanil Degradation in Irrigated Rice Field Waters using HPLC-UV and Confirmation by GC-MS
}

\author{
Ednei G. Primel, ${ }^{*, a}$ Renato Zanella, ${ }^{*, b}$ Márcia H.S. Kurz, ${ }^{b}$ Fábio F. Gonçalves, ${ }^{b}$ Manoel L. Martins, ${ }^{b}$ \\ Sérgio L.O. Machado and Enio Marchesanc \\ ${ }^{a}$ Departamento de Química, Fundação Universidade Federal do Rio Grande, \\ 96201-900 Rio Grande-RS, Brazil \\ ${ }^{b}$ Departamento de Química, ${ }^{c}$ Departamento de Fitotecnia, Universidade Federal de Santa Maria, \\ 97105-900 Santa Maria-RS, Brazil
}

\begin{abstract}
O estudo avalia a degradação do herbicida propanil e de seu principal produto de degradação, a 3,4-dicloroanilina (3,4-DCA), em água de irrigação de lavouras de arroz irrigado no Estado do Rio Grande do Sul, Brasil. Além disso, estima, também, o risco de contaminação das águas de superfície das proximidades. Após uma etapa de extração em fase sólida, a concentração de ambos os compostos foi determinada por cromatografia líquida de alta eficiência com detecção na região do ultravioleta. A confirmação foi realizada por cromatografia gasosa-espectrometria de massas. A concentração de propanil nas amostras de água variou de 0,1 a $3600 \mu \mathrm{g} \mathrm{L} \mathrm{L}^{-1}$. O propanil degradouse rapidamente em 3,4-DCA, sendo que altas concentrações deste produto foram encontradas, variando entre 1,0 e $567,5 \mu \mathrm{g} \mathrm{L} \mathrm{L}^{-1}$. Os tempos de meia-vida para o propanil em água sob condições reais nas safras de 2001, 2002 e 2003 foram 18,2, 12,5 e 12,2 h, respectivamente.
\end{abstract}

This study evaluates the degradation of the herbicide propanil and of its major degradation product, 3,4-dichloroaniline (3,4-DCA) in water from irrigated rice farming in the State of Rio Grande do Sul, Brazil. It also assesses the contamination risk of surrounding surface waters. After a solid phase extraction step, the concentration of both compounds was determined by high performance liquid chromatography with ultraviolet detection. Confirmation was conducted by gas chromatography-mass spectrometry. Concentrations of propanil in water samples varied from 0.1 to $3600 \mu \mathrm{g} \mathrm{L}^{-1}$. Propanil was degraded very rapidly to 3,4-DCA and high concentrations of this product were found, varying from 1.0 to $567.5 \mu \mathrm{g} \mathrm{L}^{-1}$ in water. The obtained half-life times for propanil in water under real conditions for the 2001, 2002 and 2003 harvests were $18.2,12.5$ and $12.2 \mathrm{~h}$, respectively.

Keywords: propanil, degradation, rice fields, water analysis, herbicide residues

\section{Introduction}

Although agriculture is just one of the countless nonpoint sources of contamination, it is generally targeted as the largest source among all pollutant categories. In Brazil, the degree to which these pollutants contribute to deteriorate water quality has not been quantified. In the United States, however, it is admitted that 50 to $60 \%$ of the pollutant load in lakes and rivers comes from agriculture. ${ }^{1}$ The rice irrigated culture in Brazil, is notable in the Rio

*e-mail: rzanella@base.ufsm.br, dqmednei@furg.br
Grande do Sul State, comprising $73 \%$ of the cultivated area of this culture. In most of the rice farms, the pesticide applications are made after the irrigation, directly in the water. Depending on the water producer's handling and on the occurrence of rain after pesticide application, there is a risk that residues of these compounds be carried out of the area, contaminating water sources. ${ }^{2-5}$

In the pre-germinated system of irrigated rice cultivation, frequently employed in Brazil, area drainage after sowing set off serious environmental problems, as well as, may cause suspended nutrients and/or pesticides losses in the released irrigation water. This has been 
evidenced in studies carried out by Primel $^{6}$ and Machado, ${ }^{7}$ in which the occurrence of some herbicides, mainly those that present high persistence, was confirmed in river and irrigation waters. Very little, up to now, has been done in Brazil to study the behavior and destination of herbicides in the system, as an attempt to maintain treatments' efficiency at a lower risk of environmental damage. ${ }^{8}$

Propanil (3,4-dichloropropionanilide) presented in Figure 1A, CAS RN 709-98-8, is one of the most used herbicides in the cultivation of irrigated rice in Brazil. It is a post-emergent selective contact herbicide with short duration used to control the electron transport inhibition of photosynthesis in herbs of wide leaves. ${ }^{9}$ According to Barceló et al. ${ }^{10}$ propanil was also one of the most used in Ebre Delta wetland area (Tarragosa, Spain) and, according to Coupe et al., ${ }^{11}$ it was extensively used in the Mississipi Delta area (USA). Various studies ${ }^{10,12-15}$ have verified that the herbicide propanil is degraded quickly into 3,4dichloroaniline (3,4-DCA), presented in Figure 1B, CAS RN 95-76-1.

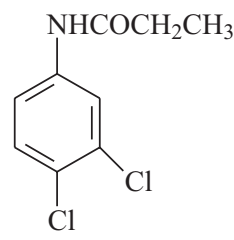

A

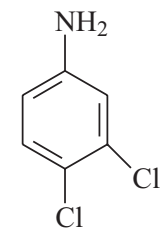

B
Figure 1. Structure of the herbicide propanil (A) and of the metabolite 3,4-DCA (B).

The meaningful contribution of this study was the development of an analytical method and its application to determine the persistence of propanil herbicide in irrigated rice farm waters. Field experiments carried out tracked propanil degradation and determined its half-life time under field conditions at experimental areas. Therefore, it was possible to assess the contamination risk of adjacent surface waters. The determination of propanil and 3,4-DCA was done by high performance liquid chromatography with ultraviolet detection (HPLC-UV) and gas chromatography-mass spectrometry (GC-MS) was used for confirmation.

\section{Experimental}

\section{Instrumentation}

An HPLC-UV system Shimadzu (Tokio, Japan) was equipped with an isocratic pump LC-10AD, a UV-visible spectrophotometric detector SPD-10 AV, an integrator CR6A, an analytical column Bondesil C18 $(250 \times 4.6 \mathrm{~mm}$ i.d.; $5 \mathrm{~mm})$ and a pre-column of the same material $(20 \times$ $1 \mu \mathrm{m}$ ), both from Varian (Palo Alto, USA).

The GC-MS system was a Varian model 3800 equipped with an injector model 1079, a capillary column VF 5MS low bleed of $30 \mathrm{~m}$ length $\times 0.25 \mathrm{~mm}$ i.d., $0.25 \mu \mathrm{m}$ film (Varian) and an autosampler model AS8200 with a carrousel for 48 vials, coupled to a mass spectrometer Varian model Saturn 2000, ion trap type, operating with a scan range between 10 to $650 \mathrm{~m} / \mathrm{z}$ and an electron impact (EI) ionization at $70 \mathrm{eV}$. The scan time was $0.90 \mathrm{~s}$ and $1.0 \mu \mathrm{L}$ injections were made. The data acquisition system was a Saturn GC/MS Workstation, version 5.51.

A vacuum pump Leybold-Heraeus D3 (Germany), a SPE manifold Varian for the simultaneous preconcentration of 20 samples, a pH meter Cole Parmer (Illinois, USA) series 500 and an ultra-sound bath Bandelin Sonorex RK 510 (Berlin, Germany) were also used.

\section{Reagents, solvents and samples}

Water used in the preparation of all the solutions was purified in a Milli-Q system (resistivity of $18.2 \mathrm{M} \Omega \mathrm{cm}$ ). Methanol ChromAR HPLC, dichloromethane residue degree (Mallinckrodt, NJ, USA) and phosphoric acid p.a. 85\% (Merck, Darmstadt, Germany) were also used. Analytical stock solutions were individually prepared through the dissolution in methanol of the respective solid reference standard of propanil (99.3\% of purity) and 3,4DCA (99.5\% purity), both from ChemService (West Chester, PA, USA). After preparation, the solution was stored in amber flask glass at $-18{ }^{\circ} \mathrm{C}$.

\section{Description of the field experiment}

The experiments were carried out together with the Crop Science Department from the Federal University of Santa Maria (UFSM) in the experimental fields at the campus, located in the central region of Rio Grande do Sul State, Brazil. The experiments were conducted in the agricultural years of 2001, 2002 and 2003 from November to March. The soil was of medium texture, with $22 \%$ of clay and $1.9 \%$ of organic matter. The experiment was entirely randomized with four repetitions. Fields of $16 \mathrm{~m}^{2}$ $(4 \times 4 \mathrm{~m})$ for each repetition were used and the commercial product Stam ${ }^{\circledR} 800$ GD was applied at a dosage of $3600 \mathrm{~g}$ of propanil per ha-1.

The pre-germinated system of cultivation was used. For the herbicide application, a precision coastal pulverizer propelled with $\mathrm{CO}_{2}$ was used, operating at a pressure of $275 \mathrm{kPa}$ and a consumption corresponding to $150 \mathrm{~L} \mathrm{ha}^{-1}$. Considering a water layer of $10 \mathrm{~cm}$, the theoretical initial 
concentration estimated for the herbicide propanil was of $3600 \mathrm{mg} \mathrm{L}^{-1}$. During the field experiments the water layer was maintained at the same level.

In the 2001 harvest, water sampling was carried out shortly before the herbicide application and on days 1,2 , 7, 14, 21, 28 and 60, after its application. In the following years, water sampling was made on days $1,2,3,5,7,10$, 14, 21, 28, 35 and 60, after herbicide application.

Water sampling was accomplished in a $1 \mathrm{~L}$ amber glass flask at $5 \mathrm{~cm}$ under the water surface. The samples were sent to the Laboratory of Analysis of Residues of Pesticides (LARP) of the Chemistry Department at UFSM for chemical analysis.

\section{Description of the analysis procedure}

All samples were analyzed as described by Primel $^{6}$ and Zanella et al. ${ }^{16} 250 \mathrm{~mL}$ aliquots, previously filtered in $47 \mathrm{~mm}$ diameter nylon membranes and $0.45 \mu \mathrm{m}$ porosity, were acidified to $\mathrm{pH} 3.0$ with phosphoric acid and pre-concentrated in a cartridge containing $500 \mathrm{mg}$ of C18. The elution was carried out with two $500 \mu \mathrm{L}$ methanol aliquots. A volume of $20 \mu \mathrm{L}$ was injected in the HPLC-UV system. As mobile phase a mixture (24:30:46; $\mathrm{v} / \mathrm{v}$ ) of methanol, acetonitrile and water was used, adjusted to $\mathrm{pH} 3.0$ with phosphoric acid, at a flow-rate of $1.0 \mathrm{~mL}$ $\mathrm{min}^{-1}$. The detection was performed by UV at $220 \mathrm{~nm}$.

The confirmation was carried out by GC-MS under the following conditions: carrier gas: helium at a constant pressure of 14 psi, resulting in an initial flow-rate of 1.2

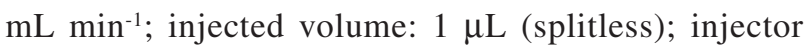
temperature of $250{ }^{\circ} \mathrm{C}$; temperature program of the column oven: $45{ }^{\circ} \mathrm{C}$, held for $1.5 \mathrm{~min}$, then a gradient of $10{ }^{\circ} \mathrm{C}$ $\min ^{-1}$ up to $260{ }^{\circ} \mathrm{C}$, maintained for 4 more min; mass spectrometer operating with the following temperatures: transfer line: $290{ }^{\circ} \mathrm{C}$, manifold: $80^{\circ} \mathrm{C}$ and ion trap: $240{ }^{\circ} \mathrm{C}$. For the GC-MS analyses, the solvent used for elution in the SPE step was evaporated using a $\mathrm{N}_{2}$ current and the remaining residue was dissolved in dichloromethane. The GC-MS acquisition data was made in the MS mode, with ion monitoring from the full scan spectrum of the compounds in study. For propanil and 3,4-DCA, the monitored ions were $\mathrm{m} / \mathrm{z} 217,161,126,90$ and 57; and 161,126 and 90, respectively.

\section{Results and Discussion}

Reversed-phase HPLC with UV detection after a solidphase extraction step proved to be a good choice for propanil and 3,4-DCA determination, allowing to evaluate these compounds concentration variation in agricultural waters. The HPLC-UV chromatographic separation profile of 3,4-DCA and propanil from a standard containing 1.0 $\mathrm{mg} \mathrm{L}^{-1}$ each compound is demonstrated in Figure 2, in which these compounds presented retention time $\left(t_{R}\right)$ values of 8.8 and 14.4 min, respectively.

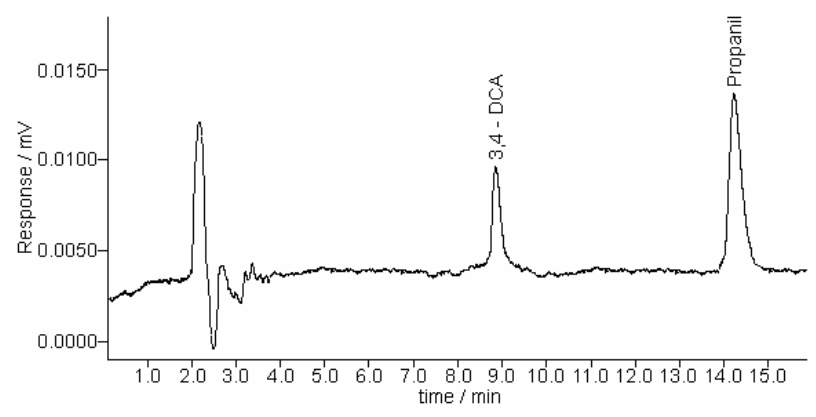

Figure 2. HPLC-UV chromatogram of 3,4-DCA and propanil from a standard at a concentration of $1.0 \mathrm{mg} \mathrm{L}^{-1}$ each.

The experimental results of 2001, 2002 and 2003 harvests are presented in Table 1. Propanil herbicide presented residues up to the seventh day after application. The sudden reduction of the concentration of propanil to $2.3 \mathrm{mg} \mathrm{L}^{-1}$ on the seventh day or to $0.1 \mathrm{mg} \mathrm{L}^{-1}$ on the fifth day, respectively in 2001 and 2003, is due to its fast hydrolysis. Available data indicate that propanil does not persist for a long time in the atmosphere, being metabolized in the matrix soil/water. However, propanil and its metabolite 3,4-DCA can constitute a risk for surface waters and for human health. ${ }^{17}$ Observational water studies carried out in the US ${ }^{18}$ showed that $3 \%$ of 1560 analyzed samples contained propanil concentration up to $2 \mu \mathrm{g} \mathrm{L}^{-1}$ and in $50 \%$ of the samples, 3,4-DCA was detected up to $8.9 \mu \mathrm{g} \mathrm{L}^{-1}$.

Table 1. Results obtained in the three harvests in the study of the propanil and 3,4-DCA

\begin{tabular}{lcccccc}
\hline \multirow{2}{*}{$\begin{array}{l}\text { Days after } \\
\text { application }\end{array}$} & \multicolumn{3}{c}{ Propanil/( $\left.\mathrm{g} \mathrm{L} \mathrm{L}^{-1}\right)$} & \multicolumn{3}{c}{$3,4-\mathrm{DCA} /\left(\mu \mathrm{g} \mathrm{\textrm {L } ^ { - 1 } )}\right.$} \\
& 2001 & 2002 & 2003 & 2001 & 2002 & 2003 \\
\hline 1 & 3600 & 3445 & 1630 & 112.3 & 104.5 & 195.1 \\
2 & 1244 & 2285 & 283 & 352.5 & 265.8 & 380 \\
3 & n.c. & 4.0 & 129 & 411.4 & 567.5 & 316.5 \\
5 & n.c. & 21.5 & 0.1 & n.c. & 166.8 & 96.7 \\
7 & 2.3 & 50.1 & n.d. & 65.2 & 12.0 & 37.9 \\
10 & n.c. & 0.1 & n.d. & n.c. & 5.2 & 3.5 \\
14 & n.d. & n.d. & n.d. & 1.6 & 1.0 & n.d. \\
\hline
\end{tabular}

n.c. $=$ not collected; n.d. $=$ not detected

For propanil herbicide, results indicate that the concentration decreases quickly during the first days, in the 2001 harvest. 3,4-DCA concentration increases until the $3^{\text {rd }}$ day and then starts to decrease. 3,4-DCA is detected up until the second week after propanil application as can 
be observed in Table 1. On the $14^{\text {th }}$ day after its application, 3,4-DCA presence was still detected at a concentration of $1.6 \mu \mathrm{g} \mathrm{L}^{-1}$.

In the 2002 harvest, propanil concentration decreases until the $3^{\text {rd }}$ day, increasing in the samples collected on the $5^{\text {th }}$ and $7^{\text {th }}$ days and then decreases again. Herbicide residues were found up until the $10^{\text {th }}$ day after application. 3,4-DCA was detected until the $14^{\text {th }}$ day, as may be observed in Table 1 , in which its concentration reached $1.0 \mu \mathrm{g} \mathrm{L}^{-1}$.

In the 2003 harvest, propanil concentration remains high $\left(129 \mu \mathrm{g} \mathrm{L}^{-1}\right)$ until the $3^{\text {rd }}$ day after application. No propanil herbicide residues are found after this, whereas $3,4-\mathrm{DCA}$ presence is detected until the $10^{\text {th }}$ day after the herbicide application, as may be observed in Table 1, in which its concentration was $3.5 \mu \mathrm{g} \mathrm{L} \mathrm{L}^{-1}$.

Propanil and 3,4-DCA confirmation, as accomplished by GC-MS, and their chromatographic profiles are presented in Figure 3, in which they showed $t_{R}$ values of 14.2 and $19.6 \mathrm{~min}$, respectively. Propanil and 3,4-DCA mass spectra monitoring ion $\mathrm{m} / \mathrm{z}, 126$ are presented in Figures 4 and 5, respectively. The main fragments identified, their relative intensities and $\mathrm{m} / \mathrm{z}$ relation are shown in Table 2.

Spectra and chromatograms obtained by sample injection were compared to those of standard analytical

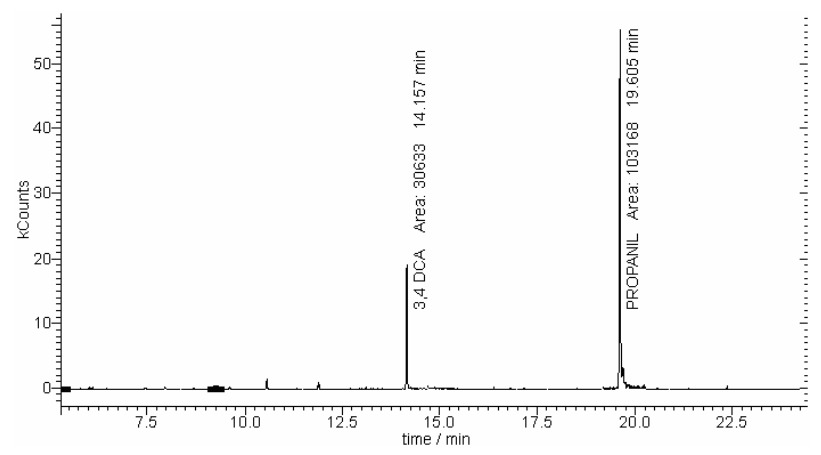

Figure 3. GC-MS chromatogram of 3,4-DCA and propanil.

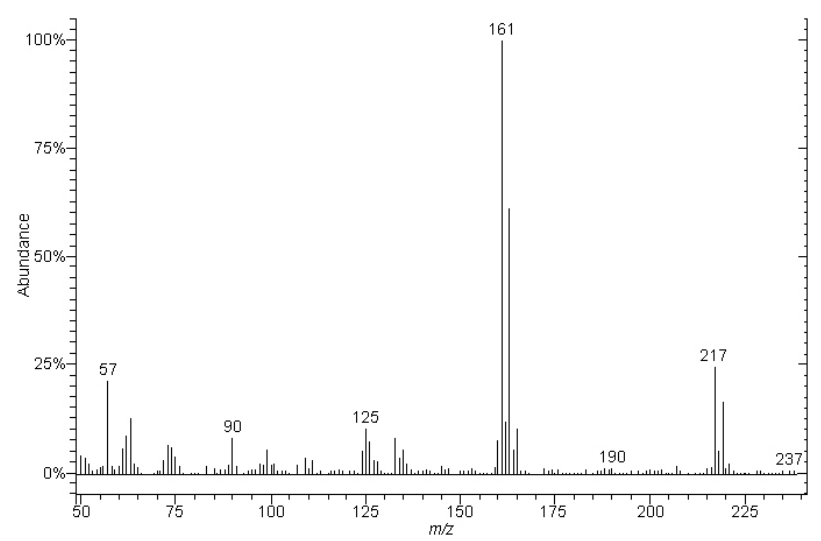

Figure 4. Mass spectra obtained for propanil by GC-MS.

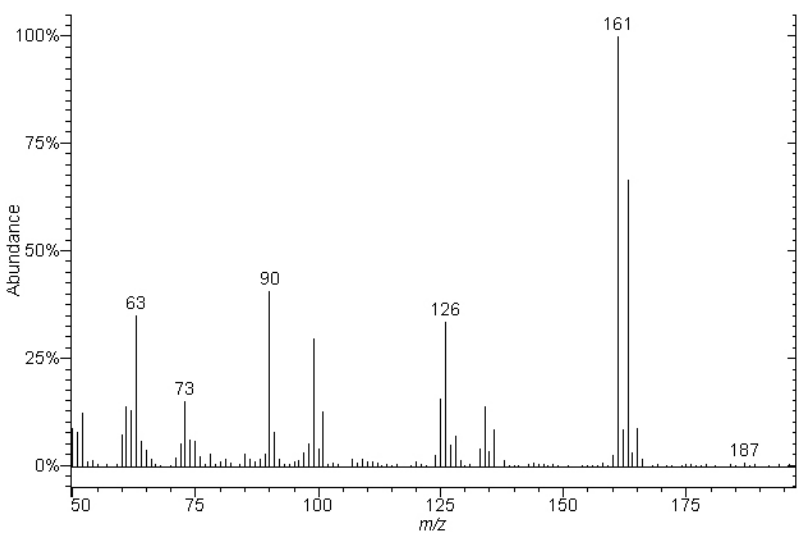

Figure 5. Mass spectra obtained for 3,4-DCA by GC-MS.

Table 2. Ion fragments obtained for propanil and 3,4-DCA by GC-MS operating in the positive mode

\begin{tabular}{lcc}
\hline Compound & $\begin{array}{c}\text { Molecular } \\
\text { mass }\end{array}$ & $\begin{array}{c}\mathrm{m} / z \text { (relative intensity) } \\
\text { [characteristic ions] }\end{array}$ \\
\hline \multirow{3}{*}{ 3,4-DCA } & 162 & $161(100 \%)[\mathrm{M}-\mathrm{H}]^{+}$ \\
& & $126(30 \%)[\mathrm{M}-\mathrm{H}-\mathrm{Cl}]^{+}$ \\
& & $20(40 \%)\left[\mathrm{M}-\mathrm{H}-\mathrm{Cl}_{2}\right]^{+}$ \\
Propanil & $218(25 \%)[\mathrm{M}-\mathrm{H}]^{+}$ \\
& & $161(100 \%)\left[\mathrm{M}-\mathrm{H}-\mathrm{COCH}_{2} \mathrm{CH}_{3}\right]^{+}$ \\
& & $\left.90(12,5 \%)\left[\mathrm{M}-\mathrm{H}_{2} \mathrm{PhN}_{2}^{+}\right]_{3}\right]^{+}$ \\
& & $57(25 \%)\left[\mathrm{M}-\mathrm{H}-\mathrm{PhCl}_{2} \mathrm{NH}_{2}\right]^{+}$ \\
\hline
\end{tabular}

solutions for these compounds. This ion selection allowed a larger selectivity in the identification of propanil and 3,4-DCA, isolating the signal of these compounds from the signals of impurities present in the samples.

\section{Determination of the half-life time}

$\ln \mathrm{C} / \mathrm{Co}=-\mathrm{kt}$ equation can be used to determine the order of a reaction if the reagent concentration as a time function is known. One way of characterizing the systems is by the determination of the half-life time $\left(\mathrm{t}_{1 / 2}\right)$ of the reagent. Then, if we plot $\ln \mathrm{C}$ as a function of $\mathrm{t}$, we will obtain a straight line, whose angular coefficient (rate constant) is - $\mathrm{k}$. Also this constant $-\mathrm{k}$ is detemined by the nature of reagents for a given temperature and is a numerical value characteristic of each reaction.

In order to calculate propanil half-life time in irrigation waters, we used $t_{1 / 2}=\ln 2 / \mathrm{k}$ equation, in which $\mathrm{k}$ is the slope of the straight line. The mean half-life time for propanil was $18.2 \mathrm{~h}$ for the 2001 harvest, $12.5 \mathrm{~h}$ for 2002 and $12.2 \mathrm{~h}$ for 2003 . These values are in accordance with propanil $_{1 / 2}$ values in water for 1-2 days reported by other authors. ${ }^{9,10}$ According to Barceló et al. ${ }^{10}$ propanil degradation is directly dependent on the environmental 
conditions and on the pesticide application rate. An increase of the sun irradiation time was observed in the last two years of this study, suggesting that this could be the main cause for the observed $t_{1 / 2}$ reduction.

\section{Conclusions}

According to the results obtained, it can be recommended that irrigation waters should be maintained for at least 10 days, after propanil herbicide application, before release into the environment, thereby avoiding watercourse contamination. It was also possible to observe in water samples from experimental irrigated rice farms, where herbicide was applied, that propanil was quickly degraded into 3,4-DCA, its main degradation product. These results made the determination of propanil halflife time in irrigation water possible. The average time were $18.2,12.5$ and $12.2 \mathrm{~h}$, respectively, for 2001, 2002 and 2003 harvests.

GC-MS analysis allowed propanil and 3,4-DCA identification, thereby confirming the results obtained by HPLC-UV.

\section{Acknowledgments}

The authors thank the National Council of Technological and Scientific Development (CNPq), The State of Rio Grande do Sul Research Foundation (FAPERGS) and Graduate Personnel Improvement Agency (CAPES) for financial support and fellowships.

\section{References}

1. Gburek, W.J., Sharpley, A.N.; J. Environ. Qual. 1997, 27, 267.

2. Primel, E.G., Zanella, R., Kurz, M.H.S., Gonçalves, F.F., Machado, S.L. O., Marchezan, E.; Quim. Nova 2005, 28, 605.
3. Jury, W. A., Russo, D., Streile, G., Elabde, H.; Water Resour. Res. 1990, 26, 13.

4. Solomon, K.R., Baker, P.R., Dixon, K.R., Klaine, S.J., LaPoint, T.W., Kendall, R.J., Weisskopf, C.P., Giddings, J.M., Giesy, J.P., Hall, L.W., Williams, W.M.; Environ. Toxicol. Chem. 1996, 15,31 .

5. Squillace, P.J., Thurman, E.M.; Environ. Sci. Technol. 1992, 26, 538 .

6. Primel, E. G.; PhD Thesis, Universidade Federal de Santa Maria, Brazil, 2003.

7. Hermes, L. C.; Epagri 1997, 97, 68.

8. Machado, S. L. O.; PhD Thesis, Universidade Federal de Santa Maria, Brazil, 2003.

9. Tomlin, C.D.S.; The e-Pesticide Manual, Thirteenth Edition, Version 3.0, Londres, 2003.

10. Barceló, D., Santos, T.C.R., Rocha, J.C., Alonso, R.M., Martinez, E., Ibanez, C.; Environ. Sci. Technol. 1998, 32, 3479.

11. Coupe, R.H., Thurman, E.M., Zimmerman, R.; Environ. Sci. Technol. 1998, 32, 3673.

12. Barceló, D.; Hennion, M. C.; Water-Techniques and Instrumentation in Analytical Chemistry; $1^{\text {st }}$ ed., Elsevier Science B. V: Amsterdam, 1997, ch. 19.

13. Santos, T.C.R., Rocha, J.C., Barceló, D.; J. Chromatogr., A 2000, $879,3$.

14. Correa, I.E., Steen, W.C.; Chemosphere 1995, 30, 103.

15. Dahchour, A., Bitton, G., Coste, C.M., Bastide, J.; Bull. Environ. Contam. Toxicol. 1986, 36, 556.

16. Zanella, R.; Primel, E. G.; Gonçalves, F. F.; Kurz, M. H. S.; Mistura, C. M.; J. Sep. Sci. 2003, 26, 935.

17. Pastorelli, R., Catenacci, G., Guanci, M., Fanelli, R., Valoti, E., Minoia, C. Airoldi, L.; Biomarkers 1998, 3, 227.

18. http://www.epa.gov/oppsrrd1/reregistration/propanil/ fate_eco_fx04oct01.pdf, accessed in 16/07/2006.

Received: February 10, 2006 Web Release Date: May 3, 2007 